\title{
Urban air pollution, and asthma and COPD hospital emergency room visits
}

\author{
J I Halonen, ${ }^{1}$ T Lanki, ${ }^{1,2}$ T Yli-Tuomi, ${ }^{1}$ M Kulmala, ${ }^{3}$ P Tiittanen, ${ }^{1}$ J Pekkanen ${ }^{1,4}$
}

\section{See Editorial, page 574}

- Tables S1, S2 and S3, figs S1 and S2, and supplementary data are published online only at http://thorax.bmj.com/content/ vol63/issue7

${ }^{1}$ Environmental Epidemiology Unit, National Public Health Institute (KTL), Kuopio, Finland;

${ }^{2}$ Institute of Epidemiology, GSFHelmholtz Zentrum München, Germany; ${ }^{3}$ Department of Physical Sciences, University of Helsinki, Finland; ${ }^{4}$ School of Public Health and Clinical Nutrition, University of Kuopio, Finland

Correspondence to:

$\mathrm{J}$ Halonen, National Public

Health Institute (KTL),

Environmental Epidemiology

Unit, PO Box 95, FIN-70701

Kuopio, Finland;

jaana.halonen@ktl.fi

Received 4 October 2007 Accepted 22 January 2008

Published Online First

11 February 2008

\section{ABSTRACT}

Background: There is little previous information of the effects of size fractioned particulate air pollution and source specific fine particles $\left(\mathrm{PM}_{2.5} ;<2.5 \mu \mathrm{m}\right)$ on asthma and chronic obstructive pulmonary disease (COPD) among children, adults and the elderly.

Objectives: To determine the effects of daily variation in levels of different particle size fractions and gaseous pollutants on asthma and COPD by age group.

Methods: Levels of particulate air pollution, $\mathrm{NO}_{2}$ and $\mathrm{CO}$ were measured from 1998 to 2004 at central outdoor monitoring sites in Helsinki, Finland. Associations between daily pollution levels and hospital emergency room visits were evaluated for asthma (ICD10: J45+J46) in children $<15$ years old, and for asthma and COPD (ICD10: $\mathrm{J} 41+\mathrm{J} 44)$ in adults (15-64 years) and the elderly ( $\geqslant 65$ years).

Results: Three to 5 day lagged increases in asthma visits were found among children in association with nucleation $(<0.03 \mu \mathrm{m})$, Aitken $(0.03-0.1 \mu \mathrm{m})$ and accumulation $(0.1-0.29 \mu \mathrm{m})$ mode particles, gaseous pollutants and traffic related $\mathrm{PM}_{2.5}(7.8 \%(95 \% \mathrm{Cl} 3.5$ to 12.3$)$ for $1.1 \mu \mathrm{g} / \mathrm{m}^{3}$ increase in traffic related $\mathrm{PM}_{2.5}$ at lag 4). Pooled asthma-COPD visits among the elderly were associated with lag 0 of $\mathrm{PM}_{2.5}$, coarse particles, gaseous pollutants and long range transported and traffic related $\mathrm{PM}_{2.5}$ (3.9\% (95\% Cl 0.28 to 7.7$)$ at lag 0). Only accumulation mode and coarse particles were associated with asthma and COPD among adults.

Conclusions: Among children, traffic related $\mathrm{PM}_{2.5}$ had delayed effects, whereas among the elderly, several types of particles had effects that were more immediate. These findings suggest that the mechanisms of the respiratory effects of air pollution, and responsible pollutants, differ by age group.

People with asthma and chronic obstructive pulmonary disease (COPD) have been reported to be more susceptible to the adverse effects of air pollution than healthy people. ${ }^{1}$ Many epidemiological studies in Europe and North America have linked different air pollution measures with asthma and COPD hospital admissions and emergency room visits. ${ }^{2-4}$ However, the differences in the effects of air pollution on asthma and COPD among children, adults and the elderly have rarely been investigated in the same study. ${ }^{3} 5$

There is evidence that ultrafine particles $(<0.1 \mu \mathrm{m}$ in aerodynamic diameter $)$ affect our respiratory system in a disadvantageous way. ${ }^{67}$ It may be that ultrafine particles have greater respiratory effects than generally monitored respirable $\left(\mathrm{PM}_{10},<10 \mu \mathrm{m}\right)$ and fine particles $\left(\mathrm{PM}_{2.5}\right.$, $<2.5 \mu \mathrm{m})$. This argument rests on the physical and chemical characteristics of ultrafine particles, such as their higher number concentration, better lung deposition, larger surface area, ability to inhibit phagocytosis and higher toxicity. ${ }^{78}$ However, because of the limited availability of measurement data on particle size fractions, there are very few epidemiological studies evaluating the effects of size fractioned particles on exacerbation of asthma and COPD. ${ }^{39}$

In this study, we evaluated the effects of the size fractioned particulate and gaseous air pollution on daily asthma and COPD hospital emergency room visits. We also identified four $\mathrm{PM}_{2.5}$ sources and assessed their effects on the visits. The analyses were performed separately for three different age groups in order to investigate whether the effects of air pollution differ among people of various ages.

\section{MATERIAL AND METHODS}

We obtained data on hospital emergency room visits for 1998-2004 for all three public hospitals in the Helsinki metropolitan area (1 million inhabitants, $745 \mathrm{~km}^{2}$ ), Finland, from the national register. These hospitals encompass, in practice, all asthma and COPD hospital emergency room visits in the area. For asthma visits, we used International Classification of Diseases Revision 10 (ICD-10) codes J45 and J46, and for COPD codes J41 and J44. We analysed a priori chosen age groups that were children (aged $<15$ years), adults (15-64 years) and the elderly ( $\geqslant 65$ years). For adults and the elderly, we determined the associations between pollutants and pooled asthmaCOPD visits, as these conditions are difficult to distinguish. Asthma and COPD visits were also analysed separately.

We used the same outdoor air pollution data measured at urban background stations as in our earlier report. ${ }^{10}$ Missing data (maximum 2\% of days) were replaced with measurements from the closest measurement station (correlation at least 0.60 ). Briefly, daily particle size distribution was measured with a differential mobility particle sizer. Based on these measurements, the following modes were defined ${ }^{11}$ : nucleation mode $(<0.03 \mu \mathrm{m})$, Aitken mode $(0.03-0.1 \mu \mathrm{m})$ and accumulation mode $(0.1-0.29 \mu \mathrm{m})$. Particles $<0.1 \mu \mathrm{m}$ in the aerodynamic diameter were counted as ultrafine particles. Coarse particulate mass was obtained by subtracting $\mathrm{PM}_{2.5}$ from $\mathrm{PM}_{10}$.

Daily mass concentration of $\mathrm{PM}_{2.5}$ was apportioned between sources using the EPA PMF 1.1 model. ${ }^{12}$ In the source apportionment, we used, in addition to the above mentioned pollutants, $\mathrm{SO}_{2}$ and $\mathrm{SO}_{4}{ }^{2-}$ (see table $\mathrm{S} 1$ in the online supplement). We identified four source categories: traffic exhaust, long range transport, soil and road dust, 
Table 1 Percentiles of daily hospital emergency room visits, air pollution concentrations, weather variables and source specific $\mathrm{PM}_{2.5}$ in Helsinki, 1998-2004

\begin{tabular}{|c|c|c|c|c|c|c|}
\hline & Days (n) & Min & $25 \%$ & $50 \%$ & $75 \%$ & Max \\
\hline \multicolumn{7}{|l|}{ Emergency room visits } \\
\hline Asthma (age <15 y) & 2557 & 0 & 1 & 2 & 3 & 39 \\
\hline Asthma + COPD (15-64 y) & 2557 & 0 & 1 & 2 & 3 & 12 \\
\hline Asthma + COPD ( $\geqslant 65$ y) & 2557 & 0 & 1 & 3 & 4 & 12 \\
\hline \multicolumn{7}{|l|}{ Pollutants } \\
\hline Nucleation mode $\left(1 / \mathrm{cm}^{3}\right)$ & 2436 & 379 & 2673 & 4187 & 6256 & 22790 \\
\hline Aitken mode $\left(1 / \mathrm{cm}^{3}\right)$ & 2436 & 1014 & 3259 & 4096 & 5171 & 18830 \\
\hline Ultrafine particles $\left(1 / \mathrm{cm}^{3}\right)$ & 2436 & 914 & 5780 & 8203 & 11540 & 50990 \\
\hline Accumulation mode $\left(1 / \mathrm{cm}^{3}\right)$ & 2436 & 57 & 238 & 359 & 525 & 2680 \\
\hline $\mathrm{PM}_{2.5}\left(\mu \mathrm{g} / \mathrm{m}^{3}\right)$ & 2424 & 1.1 & 5.5 & 9.5 & 11.7 & 69.5 \\
\hline Coarse particles $\left(\mu \mathrm{g} / \mathrm{m}^{3}\right)$ & 2392 & 0.0 & 4.9 & 9.9 & 12.1 & 101.4 \\
\hline $\mathrm{CO}\left(\mathrm{mg} / \mathrm{m}^{3}\right)$ & 2550 & 0.1 & 0.3 & 0.5 & 0.6 & 2.4 \\
\hline $\mathrm{NO}_{2}\left(\mu \mathrm{g} / \mathrm{m}^{3}\right)$ & 2550 & 3.4 & 20.1 & 28.2 & 34.3 & 96.4 \\
\hline $0_{3}\left(\mu \mathrm{g} / \mathrm{m}^{3}\right)$ & 2550 & 1.6 & 49.3 & 63.0 & 76.6 & 159.1 \\
\hline \multicolumn{7}{|l|}{ Weather variables } \\
\hline Temperature $\left({ }^{\circ} \mathrm{C}\right)$ & 2557 & -23.2 & 0.0 & 6.2 & 13.6 & 25.4 \\
\hline Relative humidity (\%) & 2557 & 38.0 & 73.0 & 80.2 & 89.0 & 99.0 \\
\hline Barometric pressure (mbar) & 2557 & 957 & 1005 & 1012 & 1019 & 1052 \\
\hline \multicolumn{7}{|l|}{ Source specific $\mathrm{PM}_{2.5}\left(\mu \mathrm{g} / \mathrm{m}^{3}\right)$} \\
\hline Traffic exhaust & 2554 & 0 & 1.2 & 1.8 & 2.3 & 7.4 \\
\hline Long range transport & 2554 & 0 & 2.5 & 5.5 & 7.3 & 30.8 \\
\hline Soil and road dust & 2554 & 0 & 0.5 & 1.0 & 1.2 & 10.7 \\
\hline Coal/oil combustion & 2554 & 0 & 0.2 & 0.5 & 0.7 & 11.3 \\
\hline
\end{tabular}

COPD, chronic obstructive pulmonary disease.

and coal/oil combustion (see table S2 and figs S1 and S2 in the online supplement). Detailed description of the source apportionment is provided in the appendix (online). In the analyses for $\mathrm{PM}_{2.5}$ sources and emergency room visits, we used all four sources simultaneously in the model.

We analysed the associations between daily air pollution levels and emergency room visits with Poisson regression and penalised thin plate regression splines in the generalised additive models framework. We implemented modelling using $\mathrm{R}$ version 2.1.1 ${ }^{13}$ and mgcv $1.3-7$ procedure. $^{14}$

We used $24 \mathrm{~h}$ median number counts for ultrafine particles and nucleation, Aitken and accumulation mode particles because of the rightly skewed distribution of particles. For particulate mass and $\mathrm{NO}_{2}$ we used $24 \mathrm{~h}$ average concentrations, and for $\mathrm{CO}$ and $\mathrm{O}_{3}$ maximum $8 \mathrm{~h}$ moving average. Lag 0 was defined as the $24 \mathrm{~h}$ period from midnight to midnight, of the day of the visit, and lag 1 as the preceding $24 \mathrm{~h}$ period, and so on. Lags up to 5 days were tested.

We built the basic model controlling for time trend, weekdays, general holidays, weather variables (temperature, relative humidity, air pressure), and influenza and pollen episodes. The dummy variable for pollen episode was constructed based on the counts of four of the most allergenic species. More detailed description of the model building is provided in the online supplement. We also tested the differences in coefficients of pollutants between the age groups with $t$ test assuming 0 covariance between the coefficients (ie, using the formula):

$$
\mathrm{t}=\frac{\operatorname{diff} \beta_{1}-\beta_{2}}{\sqrt{\left(\mathrm{SE} \beta_{1}\right)^{2}+\left(\mathrm{SE} \beta_{2}\right)^{2}}}
$$

To avoid over-smoothing and to define the amount of autocorrelation in the residuals, we did visual inspection of the smoothed curves and partial autocorrelograms of the residuals. All results are provided as per cent change in hospital emergency room visits for an interquartile increase in the pollutant concentration.

\section{RESULTS}

There were a total of 4807 asthma hospital emergency room visits among children, and 6312 and 7239 pooled asthma-COPD visits among adults and the elderly, respectively. Descriptive data for daily hospital emergency room visits, pollutant concentrations and weather variables are shown in table 1.

Correlation of ultrafine particles with $\mathrm{NO}_{2}, \mathrm{CO}$ and traffic related $\mathrm{PM}_{2.5}$ was moderate or high $(0.65,0.45$ and 0.74 , respectively). Gaseous pollutants $\mathrm{NO}_{2}$ and $\mathrm{CO}$ correlated moderately with each other (0.43). Of the particulate measures, nucleation mode particles correlated highly with ultrafine particle counts (0.92), and accumulation mode particles with $\mathrm{PM}_{2.5}$ (0.88). The correlations between pollutants, weather variables and source specific $\mathrm{PM}_{2.5}$ are given in table S1 (online).

All particle fractions below $250 \mathrm{~nm}$, and $\mathrm{NO}_{2}$ and $\mathrm{CO}$ were associated with asthma emergency room visits for children at 3-5 day lags (table 2). Asthma visits from children were also associated with ultrafine particles at lags $4 \quad(6.6 \% \quad(95 \%$ confidence interval (CI) 2.34 to 11.0$))$ and 5 (6.7\% (95\% CI 2.48 to 11.0$)$ ).

When more accurate particle size segregation was used, nucleation mode was associated with asthma visits of children with a lag of 5 day (5.4\% (95\% CI 0.74 to 10.2$)$ ), compared with Aitken mode with lags of 3,4 and 5 days, and accumulation mode with lags of 3 and 4 days (fig 1 ). We found positive associations for the pooled asthma-COPD visits of the elderly with $\mathrm{PM}_{2.5}$, accumulation mode particles, coarse particles, $\mathrm{CO}$ and $\mathrm{NO}_{2}$ at short lags (table 2). Among adults, the current day coarse and accumulation mode particle levels were statistically significantly associated with the pooled asthma-COPD visits, and the effect estimate for ultrafine particles was also considerable. 
Table 2 Per cent change in the asthma and pooled asthma-COPD hospital emergency room visits by age group for interquartile increases in pollutants in Helsinki, 1998-2004

\begin{tabular}{|c|c|c|c|}
\hline & $\begin{array}{l}\text { Children* } \\
\text { (\% change }(95 \% \mathrm{CI}))\end{array}$ & $\begin{array}{l}\text { Adults } \dagger \\
(\% \text { Change }(95 \% \mathrm{CI}))\end{array}$ & $\begin{array}{l}\text { Elderly: } \\
\text { (\% Change }(95 \% \mathrm{CI}) \text { ) }\end{array}$ \\
\hline \multicolumn{4}{|c|}{ Aitken mode $(0.03-0.1 \mu \mathrm{m})$} \\
\hline Lag 0 & $-0.47(-3.64$ to 2.80$)$ & $2.49 \S(0.06$ to 4.98$)$ & $2.38(-1.02$ to 5.90$)$ \\
\hline $\operatorname{Lag} 1$ & $2.03(-1.18$ to 5.34$)$ & $0.14(-2.38$ to 2.73$)$ & $1.17(-1.06$ to 3.44$)$ \\
\hline Lag 2 & $1.86(-1.24$ to 5.05$)$ & $-1.41(-3.91$ to 1.16$)$ & $1.97(-0.23$ to 4.21$)$ \\
\hline Lag 3 & $4.54 \S(1.54$ to 7.64$)$ & $1.61(-0.79$ to 4.07$)$ & $0.89(-1.31$ to 3.14$)$ \\
\hline Lag 4 & $6.03 \S(3.10$ to 9.05$)$ & 0.31 ( -2.06 to 2.73$)$ & $0.22(-1.98$ to 2.48$)$ \\
\hline Lag 5 & $5.15 \S(2.25$ to 8.14$)$ & $1.84(-0.46$ to 4.20$)$ & $1.19(-0.99$ to 3.43$)$ \\
\hline \multicolumn{4}{|c|}{ Accumulation mode $(0.1-0.29 \mu \mathrm{m})$} \\
\hline Lag 0 & $-0.44(-4.22$ to 3.49$)$ & $3.55 \S(0.61$ to 6.58$)$ & $4.49 \S$ (1.70 to 7.36$)$ \\
\hline Lag 1 & $0.28(-3.24$ to 3.93$)$ & $2.71(-0.15$ to 5.64$)$ & $2.90 \S(0.18$ to 5.69$)$ \\
\hline Lag 2 & $2.76(-0.77$ to 6.41$)$ & $0.22(-2.61$ to 3.14$)$ & $1.28(-1.42$ to 4.05$)$ \\
\hline Lag 3 & $3.96 \S(0.39$ to 7.65$)$ & $0.96(-1.91$ to 3.90$)$ & $-0.31(-3.04$ to 2.49$)$ \\
\hline Lag 4 & $3.37(-0.06$ to 6.93$)$ & $-1.38(-4.24$ to 1.57$)$ & $1.31(-1.40$ to 4.10$)$ \\
\hline Lag 5 & $2.53(-0.79$ to 5.96$)$ & $-1.09(-3.91$ to 1.82$)$ & $0.54(-2.16$ to 3.31$)$ \\
\hline \multicolumn{4}{|l|}{$\mathrm{PM}_{2.5}$} \\
\hline Lag 0 & $0.40(-2.60$ to 3.49$)$ & $1.32(-1.06$ to 3.76$)$ & $3.09 \S(0.95$ to 5.27$)$ \\
\hline Lag 1 & $-0.06(-2.94$ to 2.89$)$ & $1.46(-0.80$ to 3.77$)$ & $2.26 \S(0.16$ to 4.41$)$ \\
\hline Lag 2 & $0.41(-2.41$ to 3.32$)$ & $-0.90(-3.23$ to 1.49$)$ & $1.91(-0.19$ to 4.05$)$ \\
\hline Lag 3 & $2.52(-0.28$ to 5.41$)$ & $0.67(-1.68$ to 3.07$)$ & $-0.24(-2.37$ to 1.94$)$ \\
\hline $\operatorname{Lag} 4$ & $2.56(-0.17$ to 5.36$)$ & $-1.55(-3.88$ to 0.83$)$ & $0.49(-1.64$ to 2.65$)$ \\
\hline $\operatorname{Lag} 5$ & $1.18(-1.48$ to 3.92$)$ & $-1.79(-4.04$ to 0.53$)$ & $1.03(-1.05$ to 3.16$)$ \\
\hline \multicolumn{4}{|c|}{ Coarse particles } \\
\hline Lag 0 & $-0.81(-3.96$ to 2.44$)$ & $2.70 \S(0.21$ to 5.26$)$ & $2.45 \S(0.18$ to 4.76$)$ \\
\hline Lag 1 & $-1.46(-4.59$ to 1.78$)$ & $1.47(-0.79$ to 3.78$)$ & $0.65(-1.64$ to 2.99$)$ \\
\hline Lag 2 & $-0.38(-3.49$ to 2.82$)$ & $1.56(-0.72$ to 3.90$)$ & $0.40(-1.90$ to 2.76$)$ \\
\hline $\operatorname{Lag} 3$ & $-3.31(-6.34$ to -0.19$)$ & $0.67(-1.74$ to 3.14$)$ & $0.23(-2.00$ to 2.51$)$ \\
\hline Lag 4 & $1.21(-1.67$ to 4.17$)$ & $0.54(-1.85$ to 2.98$)$ & $0.59(-1.57$ to 2.80$)$ \\
\hline $\operatorname{Lag} 5$ & $2.55(-0.24$ to 5.41$)$ & $0.91(-1.51$ to 3.40$)$ & $2.62 \S(0.50$ to 4.78$)$ \\
\hline \multicolumn{4}{|l|}{$\mathrm{CO}$} \\
\hline $\operatorname{Lag} 0$ & $-1.85(-4.93$ to 1.34$)$ & $-0.81(-3.47$ to 1.92$)$ & $3.68 \S(1.20$ to 6.22$)$ \\
\hline Lag 1 & $0.80(-2.27$ to 3.96$)$ & $-2.12(-4.76$ to 0.60$)$ & $1.51(-0.91$ to 4.00$)$ \\
\hline Lag 2 & $0.58(-2.44$ to 3.70$)$ & $-1.98(-4.56$ to 0.66$)$ & $2.45 \S(0.07$ to 4.88$)$ \\
\hline Lag 3 & $0.74(-2.26$ to 3.84$)$ & $0.81(-1.73$ to 3.43$)$ & $0.57(-1.85$ to 3.04$)$ \\
\hline Lag 4 & $2.54(-0.40$ to 5.57$)$ & $-0.62(-3.16$ to 1.98$)$ & $-0.42(-2.84$ to 2.06$)$ \\
\hline Lag 5 & $4.30 \S$ (1.38 to 7.31$)$ & $0.89(-1.60$ to 3.44$)$ & $0.90(-1.48$ to 3.34$)$ \\
\hline \multicolumn{4}{|l|}{$\mathrm{NO}_{2}$} \\
\hline $\operatorname{Lag} 0$ & $-0.09(-4.56$ to 4.58$)$ & $2.69(-1.05$ to 6.57$)$ & $4.82 \S(1.26$ to 8.50$)$ \\
\hline Lag 1 & $1.92(-2.55$ to 6.59$)$ & $-0.44(-4.12$ to 3.38$)$ & $2.32(-1.12$ to 5.88$)$ \\
\hline Lag 2 & $3.61(-0.78$ to 8.19$)$ & $-1.14(-4.76$ to 2.63$)$ & $2.97(-0.43$ to 6.50$)$ \\
\hline Lag 3 & $4.53 \S(0.19$ to 9.05$)$ & $2.81(-0.81$ to 6.55$)$ & $-0.09(-3.40$ to 3.34$)$ \\
\hline Lag 4 & $10.9 \S(6.38$ to 15.5$)$ & $0.59(-1.94$ to 5.24$)$ & $-0.88(-4.15$ to 2.51$)$ \\
\hline Lag 5 & $9.36 \S(4.95$ to 14.0$)$ & $3.70 \S(0.15$ to 7.37$)$ & $1.44(-1.87$ to 4.87$)$ \\
\hline
\end{tabular}

*Model adjusted for time trend, weekday, holiday, influenza and pollen epidemics, temperature (lag 0 and 1-3 day mean), relative humidity (lag 0 and 1-3 day mean) and barometric pressure.

$\uparrow$ Model adjusted for time trend, weekday, holiday, influenza and pollen epidemics, temperature (lag 0 and 1-3 day mean), relative humidity (lag 0 ) and barometric pressure.

$\$$ Model adjusted for time trend, weekday, influenza and pollen epidemics, temperature (lag 0$)$, relative humidity $(\operatorname{lag} 0$ and $1-3$ day mean) and barometric pressure.

$\S p<0.05$.

COPD, chronic obstructive pulmonary disease.

Two pollutant models for lag days $0-5$ were then used to study whether the above observed associations between pollutants that were not too highly correlated $\left(\mathrm{PM}_{2.5}\right.$, nucleation and Aitken mode, coarse particles, $\mathrm{NO}_{2}$ and $\mathrm{CO}$ ) were independent of each other. Among children, the effect of ultrafine particles disappeared when analysed together with $\mathrm{NO}_{2}(-0.89 \%$ (95\% CI -6.11 to 4.62$)$ for ultrafine particles at lag 4). Overall, the effect of $\mathrm{NO}_{2}$ was independent of other pollutants. The estimate of the association between $\mathrm{CO}$ and asthma visits was reduced when $\mathrm{CO}$ was adjusted for $\mathrm{NO}_{2}$ or for ultrafine particles, but $\mathrm{PM}_{2.5}$ did not confound the association. Correlations between ozone and other pollutants were typically low $(-0.23$ to 0.32$)$ and therefore ozone was not included in the two pollutant models.

Among the elderly, ultrafine particles confounded the association between $\mathrm{PM}_{2.5}$ and the pooled asthma-COPD visits $\left(1.8 \%(95 \% \mathrm{CI}-0.53\right.$ to 4.1$)$ for $\mathrm{PM}_{2.5}$ at lag 1$)$. Also, the estimate for ultrafine particles reduced to 0 . The current day association for $\mathrm{PM}_{2.5}$ was reduced to $2.3 \%$ ( $95 \% \mathrm{CI}-0.01$ to 4.7 ) when analysed with $\mathrm{NO}_{2}$, and to $2.3 \%$ (95\% CI 0.09 to 4.6) 
Figure 1 Per cent change in asthma emergency room visits for children, and pooled asthma-chronic obstructive pulmonary disease visits for adults and the elderly for an interquartile range (IOR) increase in pollutant levels in 1998-2004, in Helsinki.
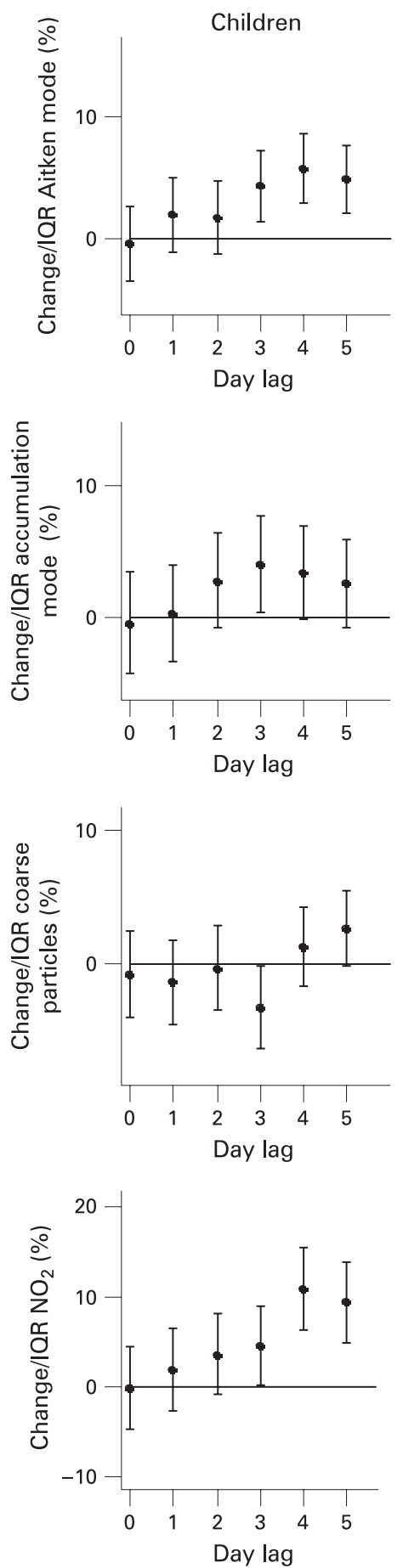

Adults
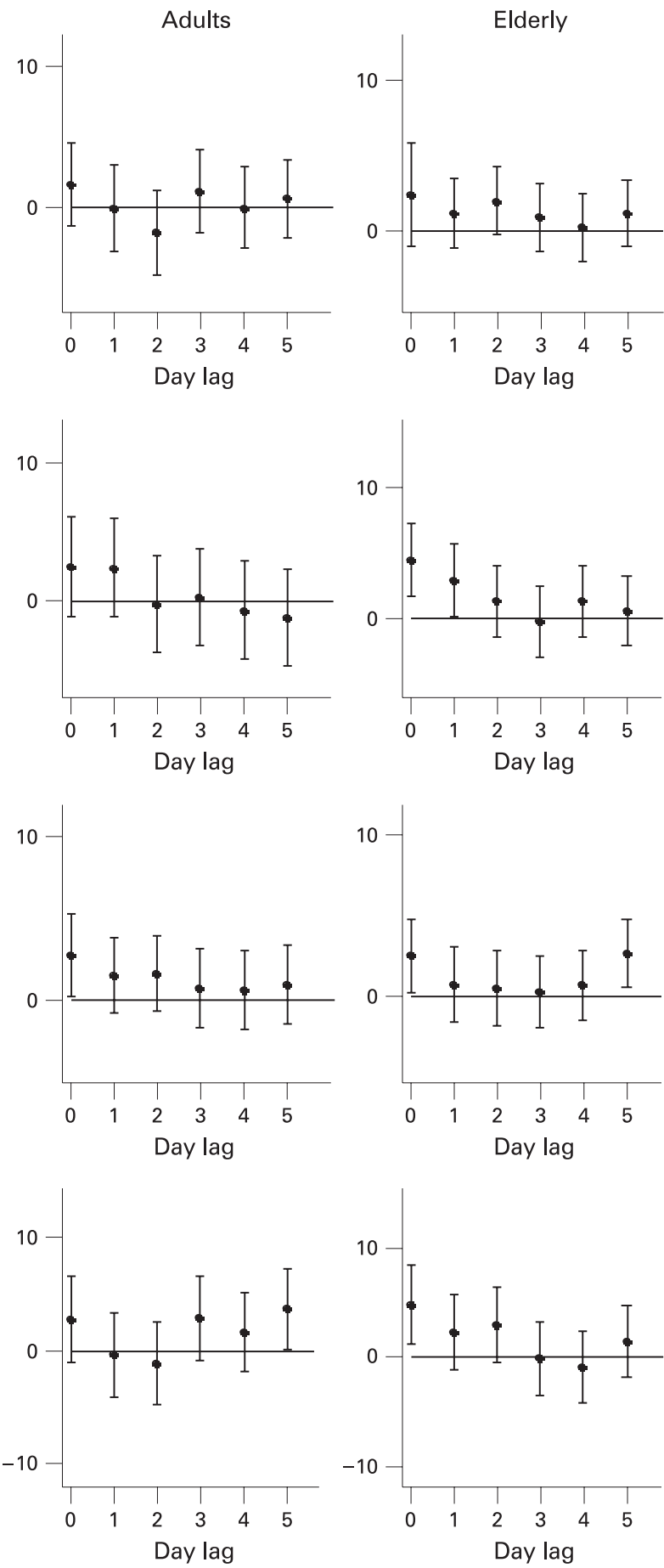

when analysed with $\mathrm{CO}$. The association of the current day coarse particles was also reduced when adjusted for ultrafine particles $(1.7 \%$ (95\% CI -0.65 to 4.10$)$ ). Very similar reductions were observed when adjusting coarse particles for $\mathrm{PM}_{2.5}, \mathrm{CO}$ and $\mathrm{NO}_{2}$. However, among adults, the observed coarse particle association was not confounded by other pollutants.

The traffic related $\mathrm{PM}_{2.5}$ had a strong and lagged effect $(7.8 \%$ (95\% CI 3.5 to 12.3 ) at lag 4) on the asthma visits of children (fig 2). Traffic related and long range transported $\mathrm{PM}_{2.5}$ had immediate effects on the pooled asthma-COPD visits of the elderly (3.9\% (95\% CI 0.2 to 7.7$)$ and $4.5 \%$ (95\% CI 1.2 to 7.9 ), respectively, at lag 0 ). Particles from soil and road dust and coal/ oil combustion were not consistently associated with any of the outcomes. Although the correlation between soil derived $\mathrm{PM}_{2.5}$ and coarse particles was high, soil related $\mathrm{PM}_{2.5}$ did not show significant associations with the emergency room visits when all four $\mathrm{PM}_{2.5}$ sources were analysed in the same model. However, when soil related $\mathrm{PM}_{2.5}$ was analysed without other sources of $\mathrm{PM}_{2.5}$, the observed association among the elderly was very similar $(2.2 \%$ (95\% CI -0.04 to 4.4$)$ for soil related $\mathrm{PM}_{2.5}$ at lag 0) to that observed with coarse particles.

The lagged effects of pollutants on asthma were larger among children than among adults and the elderly. These differences reached statistical significance $(p<0.05)$ for the coefficients of ultrafine particles (lag 4), $\mathrm{NO}_{2}$ (lag 4) and traffic related $\mathrm{PM}_{2.5}$ (lag 3 or 4 ) for adults and the elderly, and for accumulation 
Figure 2 Per cent change in asthma emergency room visits for children, and pooled asthma-chronic obstructive pulmonary disease visits for adults and the elderly for an interquartile range (IOR) increase in source specified $\mathrm{PM}_{2.5}$ in 1998-2004, in Helsinki.
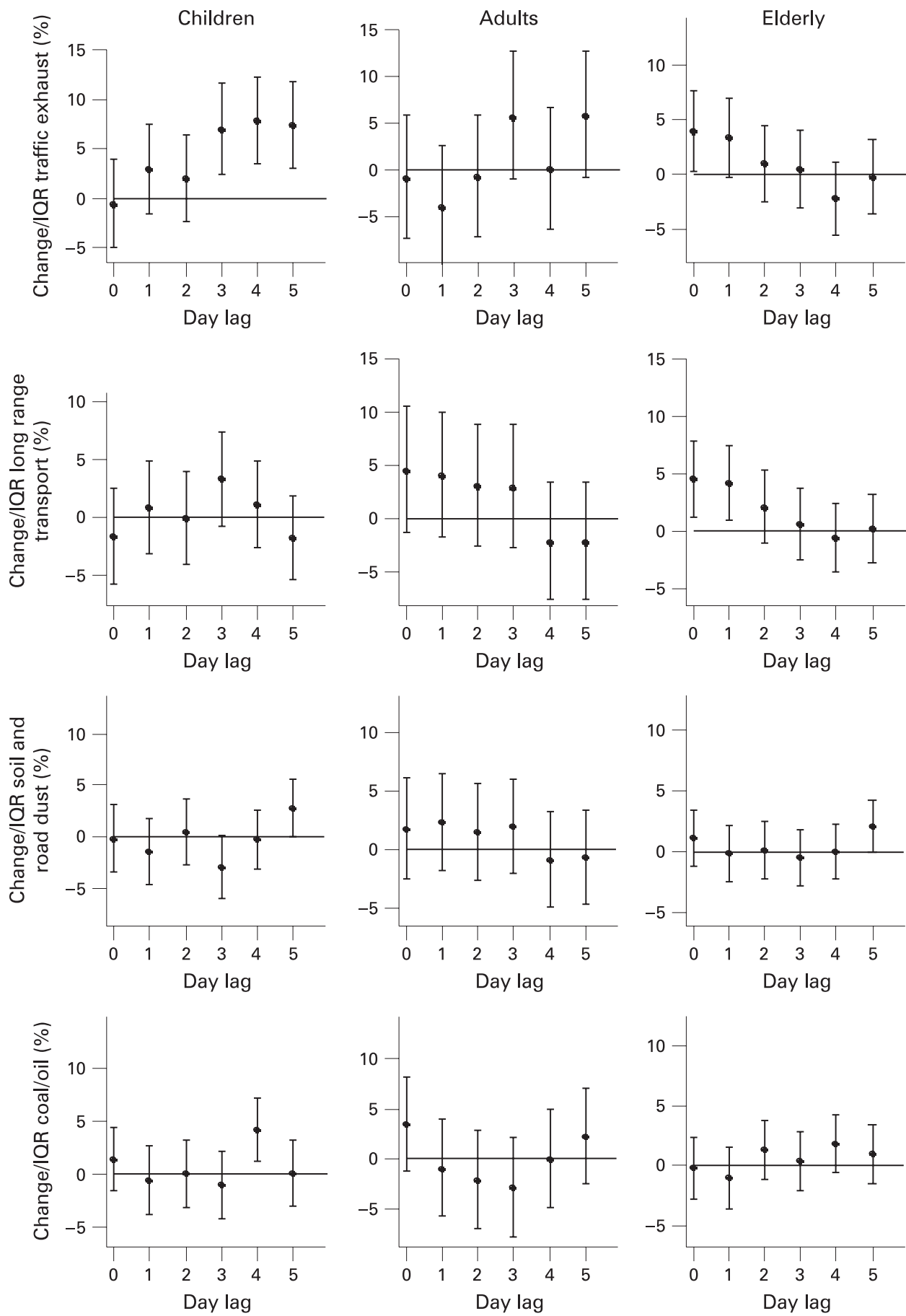

mode particles (lag 3) only among the elderly. In contrast, differences between age groups in the current day effects of pollutants reached statistical significance only for long range transported $\mathrm{PM}_{2.5}$ between children and the elderly.

As a sensitivity analysis, we used the 98th percentile cut point to estimate whether the extreme values of pollutants affected the results. To better control for the effect of temperature, we ran the analyses using the same lag for temperature and the pollutant in the models. To examine the effect of the chosen smooth function, we also ran some of the analyses using the generalised linear model with natural cubic splines with 40 degrees of freedom. We also tested 20,30, 35, 40 and 45 degrees of freedom for the time trend. In these analyses only minor changes in the results were observed.
When asthma and COPD were analysed separately, the associations of $\mathrm{PM}_{2.5}$, accumulation mode particles and $\mathrm{NO}_{2}$ with COPD were stronger than those with asthma (tables S2 and S3 online). Otherwise, the associations were similar for COPD and asthma.

An indicator variable for pollen episodes was included in all models. Leaving it out of the models increased slightly the effect of ultrafine particles on asthma visits of children $(7.0 \%$ (95\% CI 2.69 to 11.4) at lag 4). Overall controlling for pollen episodes had a minor effect on the other results.

\section{DISCUSSION}

In the current study, hospital emergency room visits for asthma among children were associated with smaller particle size 
fractions $(<250 \mathrm{~nm})$, gaseous air pollutants and traffic related $\mathrm{PM}_{2.5}$ at longer lags. In contrast, $\mathrm{PM}_{2.5}$, especially from long range transport and traffic, coarse particles and gaseous pollutants had a more immediate effect on the pooled asthma-COPD visits of the elderly. Associations in general were weaker among adults, but immediate effects of accumulation mode and coarse particles were also observed for adults. Our results are consistent with previous studies showing associations of particulate and gaseous pollutants with respiratory conditions..$^{2-5}{ }^{15-17}$ However, there are no previous studies on the effects of more accurately size fractionated particles or source specific $\mathrm{PM}_{2.5}$ on hospital emergency room visits.

The observed associations between air pollution and asthma visits among children were lagged by $3-5$ days whereas the associations among adults and elderly were more immediate. Only a few studies have determined the effects of air pollutants with time lags longer than 2 days. ${ }^{3} 1517$ However, their results support the current finding of the lagged effect among children. On the other hand, the acute effect of larger particles and gaseous pollutants is consistent with more extensive literature. ${ }^{416} 18$ The mechanism leading to the lagged effect could partly be explained by inflammation in the alveolar region of the lung caused by the smaller particles in the pollutant mixture. ${ }^{6}$ Particles in the ultrafine size fraction have been shown to be able to penetrate into the alveolar region of the lung and, in particular, in persons suffering from asthma and COPD the deposition efficiency is increased. ${ }^{19}$ The immediate effect observed among older people, on the other hand, could be a result of irritation and inflammation caused by particles deposited on the larger airways. Larger particles, such as coarse particles, and other particles larger than $1 \mu \mathrm{m}$, deposit mainly on the tracheobronchiolar regions, ${ }^{20}$ which could lead to the observed more immediate exacerbations of the diseases. Furthermore, ultrafine particles penetrate poorly indoors. As elderly people spend more time indoors, they possibly become exposed to smaller particles to a lesser degree than children. Another possible explanation for the lagged effect is behavioural reasons. Time needed for the exacerbation to become severe enough to lead to an emergency room visit can be several days. This time lag can be modified by medication use, which can differ between children and adults.

The observed associations with $\mathrm{NO}_{2}$, ultrafine particles, $\mathrm{CO}$ and traffic related $\mathrm{PM}_{2.5}$ suggest that traffic related pollutants, partly of unknown character, are the main air pollutants associated with exacerbation of asthma among children. ${ }^{21}$ In the current study, in common with several past studies, ${ }^{3} \mathrm{NO}_{2}$ was found to be a strong and independent predictor of the asthma emergency room visits of children. However, there is little toxicological evidence supporting a causal role of $\mathrm{NO}_{2}$ at current levels. ${ }^{22}$ Ultrafine particles did not have independent association with asthma, which suggests that $\mathrm{NO}_{2}$ is a better marker of traffic related pollution ${ }^{23}$ than ultrafine particles, as $\mathrm{NO}_{2}$ is more stable in the atmosphere.

We used ambient air pollution concentrations measured at fixed outdoor monitoring sites to estimate variations in personal exposure. This estimate has been shown to be good in Helsinki for $\mathrm{PM}_{2.5}{ }^{24}$ However, ultrafine particles have greater spatial variability and poorer penetration from outdoors to indoors than $\mathrm{PM}_{2.5}{ }^{25}$ and therefore ultrafine particle concentrations, such as $\mathrm{NO}_{2}$ and possibly $\mathrm{CO}$, are probably mostly indicators of daily variation in the traffic related air pollutants. However, in Helsinki, there is a fairly good correlation between different outdoor ultrafine particle measurement sites. ${ }^{26}$ Therefore, the exposure assessment for children, who spend more time outdoors than elderly people, is probably more accurate. We have also observed a correlation of 0.5 between total particle counts measured at central sites and indoors at night-time. ${ }^{27}$ The possible causal role of ultrafine particles is also supported by several toxicological studies. ${ }^{28}$

Other potentially important causal factors in traffic related air pollution are polyaromatic hydrocarbons and transition metals, such as copper $(\mathrm{Cu})$ and iron $(\mathrm{Fe})^{29}$ that contribute to the oxidative capacity of particles by increasing the formation of reactive oxygen species. Reactive oxygen species have the ability to cause pulmonary inflammation and exacerbation of lung diseases. ${ }^{30}$ However, there is a clear need to identify more accurately the causal components in traffic related air pollution, for example the compounds from diesel and gasoline vehicle emissions that we were not able to separate in our source apportionment. This was due to the lack of marker data for these compounds. The method we used for particle source apportionment, the EPA PMF, has been found to be comparable with other methods. ${ }^{31}$

For the first time, we were able to analyse the associations between respiratory emergency room visits and more accurately size fractioned particulate air pollution. We observed weaker associations of asthma with nucleation mode particles than with Aitken mode particles. The reason for this different behaviour of different particle size fractions may be that they differ in dynamics. Nucleation mode is mainly formed via atmospheric nucleation, ${ }^{32}$ but also partly directly derives from traffic emissions. Nucleation mode particles have high short term peak concentrations, so they can make significant contribution to short term exposure to inhalable particles. However, lifetime of nucleation mode particles is short, which may partly explain the observed weaker associations. At the same time, peak number concentrations of Aitken mode are smaller, but these particles are always present.

In summary, particulate and gaseous air pollution had a lagged association with asthma hospital emergency room visits among children and a more immediate effect on asthma and COPD visits among the elderly. Effects among children were observed mainly with smaller particle sizes $(<250 \mathrm{~nm})$ and traffic related $\mathrm{PM}_{2.5}$, and among the elderly with larger particles, long range transported and traffic related $\mathrm{PM}_{2.5}$. Associations in general were weaker among adults. These findings suggest that mechanisms of the respiratory effects of air pollution and the responsible air pollutants differ by age group.

Acknowledgements: We thank National Research and Development Centre for Welfare and Health, Helsinki Metropolitan Area Council, Finnish Meteorological Institute, Aerobiology Unit of University of Turku and National Public Health Institute's Infectious Diseases Register that provided the data used in this research.

Funding: The study was financially supported by the Centre of Excellence Programme 2002-2007 of the Academy of Finland (Contract 53307), the National Technology Fund (TEKES, Contract 40715/01) and the Ministry of Education (Graduate School in Environment Health SYTYKE).

Competing interests: None.

\section{REFERENCES}

1. Zanobetti A, Schwartz J, Gold D. Are there sensitive subgroups for the effects of airborne particles? Environ Health Perspect 2000;108:841-5.

2. Galan I, Tobias A, Banegas JR, et al. Short-term effects of air pollution on daily asthma emergency room admissions. Eur Respir J 2003;22:802-8.

3. Peel JL, Tolbert PE, Klein M, et al. Ambient air pollution and respiratory emergency department visits. Epidemiology 2005;16:164-73.

4. Dominici $\mathbf{F}$, Peng RD, Bell ML, et al. Fine particulate air pollution and hospital admissions for cardiovascular and respiratory diseases. JAMA 2006;295:1127-34.

5. Atkinson RW, Anderson HR, Sunyer J, et al. Acute effects of particulate air pollution on respiratory admissions. Results from APHEA 2 project. Am J Respir Crit Care Med 2001;164:1860-6. 
6. Peters A, Wichmann HE, Tuch T, et al. Respiratory effects are associated with the number of ultrafine particles. Am J Respir Crit Care Med 1997;155:1376-83.

7. Pietropaoli AP, Framptom MW, Hyde RW, et al. Pulmonary function, diffusing capacity, and inflammation in healthy and asthmatic subjects exposed to ultrafine particles. Inhal Toxicol 2004; (Suppl 1):59-72.

8. Donaldson K, Stone V, Clouter A, et al. Ultrafine particles. Occup Environ Med 2001;58:211-16.

9. Schwarze PE, Øvrevik J, Låg M, et al. Particulate matter properties and health effects: consistency of epidemiological and toxicological studies. Hum Exp Toxicol 2006;25:559-79.

10. Kettunen J, Lanki T, Tiittanen $P$, et al. Associations of fine and ultrafine particulate air pollution with stroke mortality in an area of low air pollution levels. Stroke 2007;38:918-22.

11. Hussein T, Puustinen A, Aalto PP, et al. Urban aerosol number size distributions. Atmos Chem Phys 2004:4:391-411.

12. Eberly S. EPA PMF 1.1 Users Guide. Research Triangle Park, NC: US Environmental Protection Agency, National Exposure Research Laboratory, 2005.

13. R Development Core Team. R. A language and environment for statistical computing. Vienna: R Foundation for Statistical Computing, 2005. Available from: http://www.R-project.org (accessed 7 May 2008).

14. Wood SN. Modelling and smoothing parameter estimation with multiple quadratic penalties. J R Statist Soc B 2000;62:413-28.

15. Barnett AG, Williams GM, Schwartz J, et al. Air pollution and child respiratory health. A case-cross over study in Australia and New Zeeland. Am J Respir Crit Care Med 2005;171:1272-8

16. Yang $\mathbf{0}$, Chen $Y$, Krewski D, et al. Effect of short-term exposure to low levels of gaseous pollutants on chronic obstructive pulmonary disease hospitalizations. Environ Res 2005;99:99-105.

17. Andersen ZJ, Wahlin P, Raaschou-Nielsen 0, et al. Ambient particle source apportionment and daily hospital admissions among children and elderly in Copenhagen. J Expo Sci Environ Epidemiol 2007;7:625-36.

18. Anderson HR, Ponce de Leon A, Bland JM, et al. Air pollution, pollens and daily admissions for asthma in London 1987-92. Thorax 1998;53:842-8.
19. Anderson PJ, Wilson JD, Hiller FC. Respiratory tract deposition of ultrafine particles in subjects with obstructive or restrictive lung disease. Chest 1990;97:1115-50.

20. Schulz H, Brand P, Heyder J. Particle deposition in the respiratory tract. In: Gehr J Heyder J, eds. Particle-lung interactions. New York: Decker, 2000:229-30.

21. Wong GW, Lai CK. Outdoor air pollution and asthma. Curr Opin Pulm Med 2004;10:62-6.

22. Kraft M, Eikmann T, Kappos A, et al. The German view: effects of nitrogen dioxide on human health - derivation of health-related short-term and long-term values. Int J Hyg Environ Health 2005;208:305-18.

23. WHO. Air quality guidelines, Global update 2005, particulate matter, ozone, nitrogen dioxide and sulfur dioxide. Geneva: WHO, 2005:275-80.

24. Janssen NA, Lanki T, Hoek G, et al. Associations between ambient, personal, and indoor exposure to fine particulate matter constituents in Dutch and Finnish panels of cardiovascular patients. Occup Environ Med 2005;12:868-77.

25. Pekkanen J, Kulmala M. Exposure assessment of ultrafine particles in epidemiologic time-series studies. Scand J Work Environ Health 2004;30(Suppl 2):9-18.

26. Buzorius G, Hämeri K, Pekkanen J, et al. Spatial variation of aerosol number concentration in Helsinki City. Atmos Environ 1999:33:553-65.

27. Hoek G, Kos G, Harrison R, et al. Indoor-outdoor relationships of particle number and mass in four European cities. Atmos Environ 2008;42:156-69.

28. Li N, Sioutas C, Cho A, et al. Ultrafine particulate pollutants induce oxidative stress and mitochondrial damage. Environ Health Perspect 2003;111:455-60.

29. de Kok TM, Driece HAL, Hogervorst JGF, et al. Toxicological assessment of ambient and traffic-related particulate matter: A review of recent studies. Mutat Res 2006;613:103-22.

30. Casillas AM, Hiura $\mathrm{T}$, Li N, et al. Enhancement of allergic inflammation by diesel exhaust particles: permissive role of reactive oxygen species. Ann Allergy Asthma Immunol 1999;83:624-9.

31. Thurston GD, Ito K, Mar T, et al. Workgroup Report: Workshop on Source Apportionment of Particulate Matter Health Effects-Intercomparison of Results and Implication. Environ Health Perspect 2005;113:1768-74.

32. Kulmala $\mathbf{M}$, Vehkamäki $\mathrm{H}$, Petäjä $\mathrm{T}$, et al. Formation and growth rates of ultrafine atmospheric particles: A review of observations. J Aerosol Sci 2004;35:143-76.

\section{Access the latest content chosen by our Editors}

BMJ Journals editors select an article from each issue to be made free online immediately on publication. Other material is free after 12 months to non-subscribers. Access the Editor's Choice from the home page - or expand your horizons and see what the other BMJ Journals editors have chosen by following the links on any BMJ Journal home page. 